Editor's Note: These short reviews of recent JNeurosci articles, written exclusively by students or postdoctoral fellows, summarize the important findings of the paper and provide additional insight and commentary. If the authors of the highlighted article have written a response to the Journal Club, the response can be found by viewing the Journal Club at www.jneurosci.org. For more information on the format, review process, and purpose of Journal Club articles, please see http://jneurosci.org/content/ preparing-manuscript\#journalclub.

\title{
Protecting Mitochondrial Health: A Unifying Mechanism in Adult Neurogenesis
}

\author{
(D)ajat Puri \\ Synaptic Function Section, National Institute of Neurological Disorder and Stroke, National Institutes of Health, Bethesda, Maryland 20892 \\ Review of Voloboueva et al.
}

Adult neurogenesis occurs in the hippocampal region of the brain of most mammals including humans. Adultborn neurons play a critical role in hippocampus-dependent memory formation. The importance of adult neurogenesis has been indicated by multiple studies in which dysfunctional adult neurogenesis is associated with aging and neurodegenerative disorders (Gonçalves et al., 2016). In fact, adult neurogenesis is critical for recovery from brain injury (Fallon et al., 2000; Magavi et al., 2000).

Adult neurogenesis involves a multistep process of lineage progression starting with neural stem cells (NSCs), which give rise to intermediate progenitor cells (IPCs), which in turn produce neuroblasts, which mature into neurons (Ming and Song, 2005; Fig. 1). Multiple reports have indicated that metabolic reprogramming events help to regulate the differentiation processes involved in adult neurogenesis. (Gonçalves et al., 2016). For example, NSCs are glycolytic, but mature neurons require mitochondrial respiration for ATP generation. Indeed, cellular mitochondria are essential for the differentiation

Received April 17, 2017; revised May 26, 2017; accepted June 4, 2017.

Correspondence should be addressed to Rajat Puri, Room 2B-209, Building 35, Synaptic Function Section, National Institute of Neurological Disorder and Stroke, The John Edward Porter Neuroscience Research Center, Bethesda, MD 20892. E-mail: purir2@mail.nih.gov.

DOI:10.1523/JNEUROSCI.1036-17.2017

Copyright $\odot 2017$ the authors $\quad 0270-6474 / 17 / 376603-03 \$ 15.00 / 0$ of NSCs into mature neurons. However, after brain injury, including stroke and head trauma, inflammatory responses from activated microglia cause mitochondrial damage in newly generated adult neurons, leading to significant loss in neurogenesis at the injury site (Ekdahl et al., 2003).

One way to overcome the problem of inflammation-induced mitochondrial dysfunction is to identify cellular and molecular factors that regulate mitochondrial health and dysfunction. One such factor is microRNA-210 (miR-210), which in vitro studies have shown have a role in downregulating mitochondrial function and mediating the switch to glycolysis (Chen et al., 2010; White et al., 2015). miRNAs are short, single-stranded, noncoding RNAs ( $\sim 22$ nucleotide long) that regulate gene expression by binding to target mRNAs (Huang and Zuo, 2014). In a recent issue of The Journal of Neuroscience, Voloboueva et al. (2017) investigated the effect of the loss of miR-210 on mitochondrial health and neurogenesis under conditions of inflammation in vitro.

Voloboueva et al. (2017) treated NSC cultures with media preconditioned by proinflammatory activated microglia to mimic inflammatory conditions and examined the effect of blocking miR-210 on the survival of NSC cultures under these conditions. They observed an increase in survival of differentiated NSCs and a decrease in apoptotic (TUNEL-positive) mature neurons when miR-210 was inhibited. Moreover, a significant percentage of surviving NSCs differentiated into mature neurons under inflammatory conditions with miR-210 inhibition compared with NSC cultures exposed to inflammatory injury but transfected with negative control. These effects were accompanied by an increase in the activity of two major mitochondrial enzymes, cytochrome $c$ oxidase (a component of the electron transport chain) and aconitase (a Krebs cycle enzyme). In contrast, an increase in miR-210 levels resulted in a decrease in total NSC survival and differentiated NSCs during inflammatory injury.

In the above experiments, NSC cultures were transfected with miR-210 inhibitor or negative control on days $4-5$ of differentiation and exposed to preconditioned proinflammatory media $24 \mathrm{~h}$ later. Because the previous results indicated an increase in mitochondrial function and NSC survival rate during inflammatory injury, Voloboueva et al. (2017) predicted that transfecting NSC cultures on days 1-2 after the start of differentiation would further increase mitochondrial energetics. To their surprise, miR-210 inhibition at an earlier time point resulted in a significant decrease in total NSC density (low proliferation) and differentiated NSCs compared with controls. Their observation was consistent with earlier findings suggesting that dividing stem cells depend on glycolytic metabolism rather than mito- 
chondrial bioenergetics for ATP production (Gonçalves et al., 2016). Together, these results indicate that (1) inhibiting miR210 promotes neurogenesis by protecting mitochondria in NSC cultures against inflammatory injury; and (2) for therapeutic purposes, the timing of miR- 210 inhibition is critical because it induces metabolic changes that reduce NSC proliferation capacity.

Voloboueva et al. (2017) observed that blocking miR-210 at an earlier time point altered NSC metabolism with suppression of the glycolytic pathway and an increase in mitochondrial respiratory function. To address the mechanisms for the shift in metabolic activity associated with early miR-210 inhibition in NSCs, Voloboueva et al. (2017) focused on the AMP-activated protein kinase (AMPK) signaling pathway. The intracellular energy sensor AMPK is a master regulator of energy homeostasis that responds to changes in the cellular AMP/ ATP ratio (Carling, 2017). Earlier reports have indicated that AMPK also positively regulates NSC proliferation capacity. Voloboueva et al. (2017) observed that blocking miR-210 led to a decrease in AMPK activity, which likely explains the decreased rate in NSC proliferation.

To further delineate the molecular mechanism regulating NSC proliferation, the authors focused on retinoblastoma $(\mathrm{Rb})$ protein, which is a downstream target of AMPK. Rb protein is one of the known negative regulators of cell-cycle progression in stem cell biology. It has been reported that AMPK directly phosphorylates $\mathrm{Rb}$ protein and that hyperphosphorylation of $\mathrm{Rb}$ acts as a positive regulator of NSC proliferation (Dasgupta and Milbrandt, 2009). Voloboueva et al. (2017) found that the inhibition of miR210 led to hypophosphorylation of $\mathrm{Rb}$ protein in conjunction with low NSC proliferation. Since miR-210 does not interact directly with AMPK or Rb protein (source: miRBase.org database), this loss in AMPK and Rb protein activity may be a direct consequence of metabolic changes in NSCs resulting from the block in miR210 function.

Loss of adult-born neurons resulting from defective mitochondrial function has been reported in multiple neurodegenerative disorders and in aging, as well as after brain injury. Indeed, several recent studies have examined factors that improve mitochondrial health and improve neurogenesis, often resulting in improved cognitive performance (Fig. 1). One such recent study (Richetin et al., 2017) highlighted the importance of manipulating

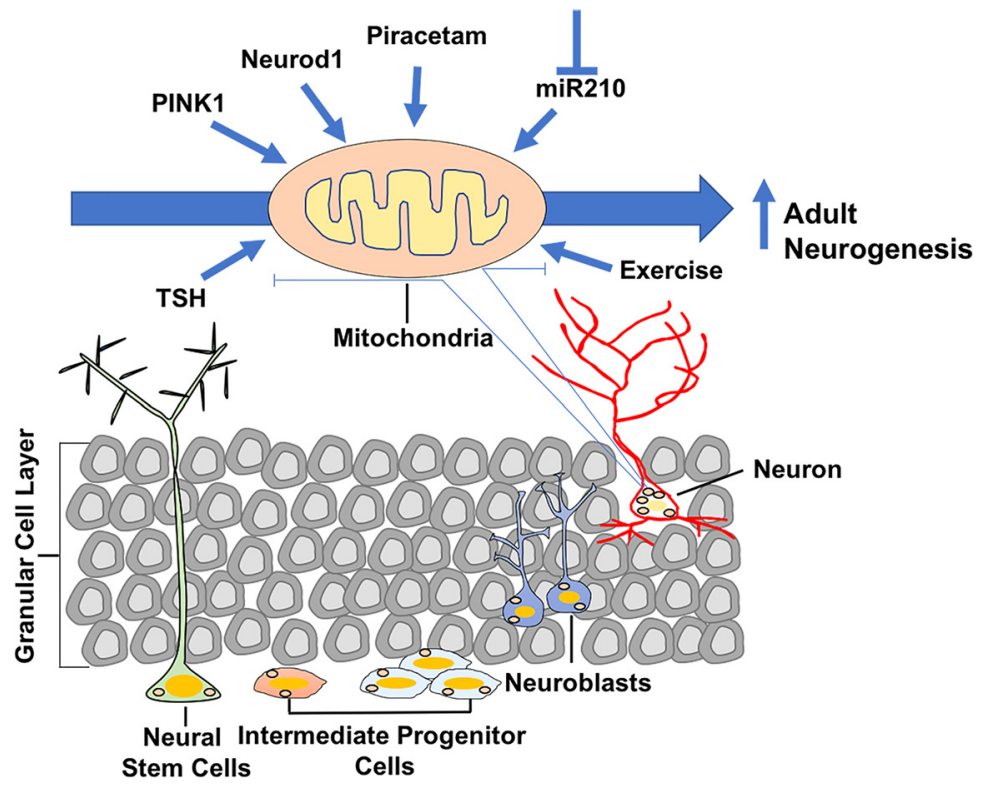

Figure 1. Schematic of the multistep lineage progression of neural stem cells to neurons during adult hippocampal neurogenesis and the factors that positively influence mitochondrial health and promote adult neurogenesis.

mitochondrial function to enhance adult neurogenesis in an Alzheimer's disease (AD) mice model. The authors observed defects in mitochondrial health that resulted in the loss of adult-born neurons in $\mathrm{AD}$ mice. They overexpressed a neurogenic bHLH transcription factor (Neurod1), which previously was reported to maintain mitochondrial mass and ATP levels under conditions of oxidative stress in neuroblastoma cells, in the brains of AD mice. Neurod1 overexpression rescued mitochondrial deficits of adult-born neurons and rescued spatial memory. Another study (Beckervordersandforth et al., 2017) investigated the effect of the memory-enhancing drug piracetam on adult neurogenesis in the brains of aged mice. Piracetam is known to enhance mitochondrial respiration, electron transport chain activity, and ATP production in cells with a loss in mitochondrial function (Keil et al., 2006). Interestingly, treatment with piracetam increased the population of IPCs and neuroblasts and ameliorated aging-related defects in hippocampal neurogenesis in aged mice. Exercise is another factor that has been linked to enhancing mitochondrial mass in adult-born neurons and promoting neurogenesis (Steib et al., 2014). A third study (Agnihotri et al., 2017) examined the effect of the loss of PTEN (phosphatase and tensin homolog)-induced kinase-1 (PINK1), a protein that helps to maintain mitochondrial health by regulating the mitophagy of dysfunctional mitochondria, on adult hippocampal neurogenesis in mice.
Loss of PINK1 was associated with mitochondrial deficits and loss in the maturation of adult born neurons in the hippocampus. Finally, multiple studies have indicated thyroid hormone therapy as a potential approach toward enhancing mitochondrial function and adult neurogenesis (Remaud et al., 2014). Defects in thyroid hormone signaling have been associated with alterations in both mitochondrial function and hippocampal neurogenesis in the aging brain (Remaud et al., 2014).

In conclusion, the findings of $\mathrm{Vo}$ loboueva et al. (2017) provide a critical mechanism underlying inflammationassociated deficits in neurogenesis. This may aid in identifying novel therapeutic strategies for treatment in several neurodegenerative diseases. Recent findings, both in vitro and in vivo, indicate a direct role of mitochondria in the modulation of adult neurogenesis and provide a strong proof of concept that protecting mitochondrial health could enhance the rate of adult neurogenesis under different neuropathological conditions.

\section{References}

Agnihotri SK, Shen R, Li J, Gao X, Büeler H (2017) Loss of PINK1 leads to metabolic deficits in adult neural stem cells and impedes differentiation of newborn neurons in the mouse hippocampus. FASEB J. Advance online publication. Retrieved June 13, 2017. doi: 10.1096/fj.201600960RR. CrossRef Medline

Beckervordersandforth R, Ebert B, Schäffner I, Moss J, Fiebig C, Shin J, Moore DL, Ghosh L, Trinchero MF, Stockburger C, Friedland K, Steib K, von Wittgenstein J, Keiner S, Re- 
decker C, Hölter SM, Xiang W, Wurst W, Jagasia R, Schinder AF, et al (2017) Role of mitochondrial metabolism in the control of early lineage progression and aging phenotypes in adult hippocampal neurogenesis. Neuron 93:560-573.e6. CrossRef Medline

Carling D (2017) AMPK signalling in health and disease. Curr Opin Cell Biol 45:31-37. CrossRef Medline

Chen Z, Li Y, Zhang H, Huang P, Luthra R (2010) Hypoxia-regulated microRNA-210 modulates mitochondrial function and decreases ISCU and COX10 expression. Oncogene 29:4362-4368. CrossRef Medline

Dasgupta B, Milbrandt J (2009) AMP-activated protein kinase phosphorylates retinoblastoma protein to control mammalian brain development. Dev Cell 16:256-270. CrossRef Medline

Ekdahl CT, Claasen JH, Bonde S, Kokaia Z, Lindvall $\mathrm{O}$ (2003) Inflammation is detrimental for neurogenesis in adult brain. Proc Natl Acad Sci U S A 100:13632-13637. CrossRef Medline

Fallon J, Reid S, Kinyamu R, Opole I, Opole R, Baratta J, Korc M, Endo TL, Duong A, Nguyen G, Karkehabadhi M, Twardzik D, Patel S, Loughlin S (2000) In vivo induction of mas- sive proliferation, directed migration, and differentiation of neural cells in the adult mammalian brain. Proc Natl Acad Sci U S A 97:14686-14691. CrossRef Medline

Gonçalves JT, Schafer ST, Gage FH (2016) Adult neurogenesis in the hippocampus: from stem cells to behavior. Cell 167:897-914. CrossRef Medline

Huang X, Zuo J (2014) Emerging roles of miR210 and other non-coding RNAs in the hypoxic response. Acta Biochim Biophys Sin (Shanghai) 46:220-232. CrossRef Medline

Keil U, Scherping I, Hauptmann S, Schuessel K, Eckert A, Müller WE (2006) Piracetam improves mitochondrial dysfunction following oxidative stress. Br J Pharmacol 147:199-208. CrossRef Medline

Magavi SS, Leavitt BR, Macklis JD (2000) Induction of neurogenesis in the neocortex of adult mice. Nature 405:951-955. CrossRef Medline

Ming GL, Song H (2005) Adult neurogenesis in the mammalian central nervous system. Annu Rev Neurosci 28:223-250. CrossRef Medline

Remaud S, Gothié JD, Morvan-Dubois G, Demeneix BA (2014) Thyroid hormone signaling and adult neurogenesis in mammals. Front Endocrinol (Lausanne) 5:62. CrossRef Medline
Richetin K, Moulis M, Millet A, Arràzola MS, Andraini T, Hua J, Davezac N, Roybon L, Belenguer P, Miquel MC, Rampon C (2017) Amplifying mitochondrial function rescues adult neurogenesis in a mouse model of Alzheimer's disease. Neurobiol Dis 102:113-124. CrossRef Medline

Steib K, Schäffner I, Jagasia R, Ebert B, Lie DC (2014) Mitochondria modify exercise-induced development of stem cell-derived neurons in the adult brain. J Neurosci 34:6624-6633. CrossRef Medline

Voloboueva LA, Sun X, Xu L, Ouyang YB, Giffard RG (2017) Distinct effects of miR-210 reduction on neurogenesis: increased neuronal survival of inflammation but reduced proliferation associated with mitochondrial enhancement. J Neurosci 37:3072-3084. CrossRef Medline

White K, Lu Y, Annis S, Hale AE, Chau BN, Dahlman JE, Hemann C, Opotowsky AR, Vargas SO, Rosas I, Perrella MA, Osorio JC, Haley KJ, Graham BB, Kumar R, Saggar R, Saggar R, Wallace WD, Ross DJ, Khan OF, et al (2015) Genetic and hypoxic alterations of the microRNA-210ISCU1/2 axis promote iron-sulfur deficiency and pulmonary hypertension. EMBO Mol Med 7:695-713. CrossRef Medline 